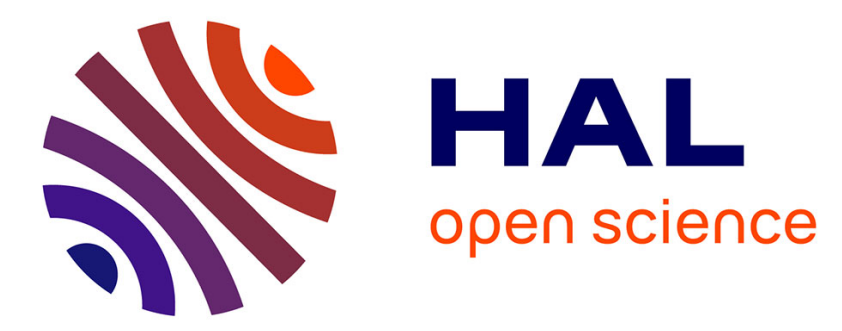

\title{
The Vicious Triangle of A Priori Truth, Contingent Truth, and Logical Truth
}

Isidora Stojanovic

\section{To cite this version:}

Isidora Stojanovic. The Vicious Triangle of A Priori Truth, Contingent Truth, and Logical Truth. Nikola Kompa, Christian Nimtz and Christian Suhm. The A Priori and its Justification in Philosophy, Kompa, N., Nimtz C., Suhm, C.; Mentis Verlag, pp.69-82, 2009. ijn_00354590

\section{HAL Id: ijn_00354590 https://hal.science/ijn_00354590}

Submitted on 20 Jan 2009

HAL is a multi-disciplinary open access archive for the deposit and dissemination of scientific research documents, whether they are published or not. The documents may come from teaching and research institutions in France or abroad, or from public or private research centers.
L'archive ouverte pluridisciplinaire HAL, est destinée au dépôt et à la diffusion de documents scientifiques de niveau recherche, publiés ou non, émanant des établissements d'enseignement et de recherche français ou étrangers, des laboratoires publics ou privés. 
Isidora Stojanovic

\title{
THE VICIOUS TRIANGLE OF A PRIORI TRUTH, CONTINGENT TRUTH, AND LOGICAL TRUTH
}

\author{
1. Introduction: Clarifying the Meaning \\ OF THE Terms >A PRIORI $<$ AND >CONTINGENT<
}

In this paper, I argue against the view there are contingent a priori truths, and against the related view that there are contingent logical truths. I will suggest that in general, predicates sa priori< and >contingent< are implicitly relativized to circumstances, and argue that apriority entails necessity, whenever the two are relativized to the same circumstance. I will then criticize the idea, inspired by David Kaplan's framework, of contingent contents »knowable under a priori characters. "I will also argue, against Kaplan, that sentences of the form »The actual $\mathrm{F}$ is $\mathrm{F}$ « do not deserve the status of logical truths, since what they express is neither necessary nor a priori (pace Kaplan).

In Naming and Necessity, Saul Kripke claims that there are contingent a priori truths. In Demonstratives, David Kaplan not only endorses this claim, but suggests that the case is even more obvious when formulated with the help of indexicals. Kaplan claims that in the »logic of indexicals, « there are many logical truths that are not necessary. The aim of the present paper is to show that there are no contingent a priori truth - or, more precisely, that something that, at a first glance, we may be tempted to call an "a priori contingent truth « is either a single thing that is a priori with respect to one circumstance and contingent with respect to another circumstance, or two different things, one of which is contingent while the other is a priori. The plan is to propose two rebuttals of Kripke's proposal (sections 2 and 3), followed by two rebuttals of Kaplan's proposal (sections 4 and 5 ), and end with some critical remarks concerning the idea of contingent logical truths. But first of all, let me clarify how I shall understand the terms a priori, a posteriori, necessary and contingent.

A necessary truth is what happens to be the case and could not fail to be the case. A contingent truth is what happens to be the case but could fail to be the case. An a priori truth is what is known, independently of any empirical input, to be the case, while an a posteriori truth is what is known to be the case only given some antecedent empirical knowledge. 
So far, the idea that there are any a priori truths is, to say the least, questionable, since, by definition, a priori truth presupposes a cognitive agent, and that agent will de facto have a great amount of empirical input - for instance, by having experience of her own cognitive processes or thoughts. It becomes unclear, then, whether the agent should ever be able to know anything a priori, as her knowledge of any given truth may always turn out to depend on some empirical knowledge regarding the cognitive processes involved in the very knowledge of that truth.

Fortunately, it does not matter much to the present discussion whether some piece of knowledge depends on the empirical input coming from the cognitive processes involved in this knowledge. A more fruitful notion of a priori truth is that of a truth that a given agent, in a given circumstance, can know independently of knowledge that depends on any empirical inputs other than those that the agent has accumulated up to that circumstance. So on this definition, a truth that is a posteriori with respect to a given circumstance will become a priori with respect to subsequent circumstances in which its knowledge is taken for granted. This is, then, a fairly weak notion of a priori truth: the focus is on truth whose knowledge does not require any further empirical investigation. I will argue that even on this weak reading of sa priori<, there aren't any contingent a priori truths.

I believe that the notions of relative contingency and necessity are also more fruitful than those of absolute contingency and necessity. A reader familiar with modal logic will immediately recall the notion of accessibility. Something is necessary relative to a given circumstance when it obtains in all the circumstances accessible from that circumstance. For example, consider the actual circumstance, in which (as of now) Paris is the capital of France. Suppose that only those circumstances, in which it remains true that in 2009, Paris is the capital of France, are metaphysically accessible from these circumstances. Then, with respect to the actual circumstances, it is necessary that Paris is the capital of France. Of course, we do not want to be committed to determinism, and we do want to say that it could have happened that some place other than Paris were the capital of France. Another way of saying this is to say that the truth that in 2009, Paris is the capital of France, while being necessary with respect to circumstances in which it is settled that Paris is the capital of France (as the actual circumstances), is only a contingent truth with respect to circumstances in which it is not yet settled what would be the capital of France (as, say, one century ago).

The metaphysical picture underlying the present discussion is one in which the accessibility relation is a partial order (as in the system of modal logic known as S4), rather than an equivalence relation (as it is in S5). This choice comes naturally once it is agreed that the notions of relative contingency and necessity are more fruitful than those of absolute contingency or necessity. For, a system such as S5, in which, within a given equivalence class, every point is accessible from every other point, trivializes the notion of accessibility and collapses relative contingency/necessity into absolute contingency/necessity. 
If we agree to understand the terms along the lines sketched above, we should be inclined to think that if something is a priori then it is necessary, and if something is contingent, then it is a posteriori. Here is why. Take any agent $a$, any circumstance $c$, and any truth $p$. Suppose that in $c$, a's knowledge gathered prior to $c$ (empirically or otherwise) is all that $a$ needs in order to know that $p$ holds. But then, $p$ could no longer fail to hold in $c$. For if $p$ failed to hold in $c$, $a$ 's knowledge gathered prior to $c$ would not have sufficed for $a$ to know that $p$ holds in $c$ - which contradicts our assumption that in $c, a$ knows a priori that $p$ holds.

\section{Kripke on the Contingent A Priori}

My claim, for which I have just outlined an argument, is that what is known a priori to be the case could not fail to be the case; in other words, what is known a priori is necessary. How come, then, that the idea that there are contingent a priori truths has been received with so much enthusiasm? Let me trace the issue back to Kripke:

What then, is the epistemological status of the statement s Stick $S$ is one metre long at to <, for someone who has fixed the metric system by reference to stick $S$ ? It would seem that he knows it a priori. For if he used stick $S$ to fix the reference of the term >one metres, then as a result of this kind of >definition ( which is not an abbreviative or synonymous definition), he knows automatically, without further investigation, that $S$ is one metre long. On the other hand, even if $S$ is used as a standard of a metre, the metaphysical status of the statement `Stick $S$ is one metre long< will be that of a contingent statement, provided that >one metre is regarded as a rigid designator: under appropriate stresses and strains, heatings or coolings, $S$ would have had a length other than one metre even at $t_{0}$. (Such statements as >The water boils at 100 degrees centigrade, at sea level can have a similar status.) So in this sense, there are contingent a priori truths. ${ }^{1}$

Kripke is cautious enough here to qualify his claim that there are contingent a priori truths with an »in this sense«. But in what sense exactly? Presumably, the term sontingent< is taken in an absolute sense. For, suppose that it were relativized to a circumstance in which one has used stick $S$ as a standard of a meter, and assume furthermore that the only circumstances accessible from that circumstance are those in which it is settled that stick S has been used as a standard of a meter. ${ }^{2}$

\footnotetext{
${ }^{1}$ Kripke (1980: 56).

2 The plausibility of this assumption is conditional on our assumptions regarding the accessibility relation at stake. I am assuming, as previously mentioned, that if we have a circumstance in which some event $e$ (such as using stick $S$ as a standard of a meter) has occurred, then in all the accessible circumstances, $e$ has occurred. This means that, for example, the relation of epistemic indistinguishability is not a good candidate for our accessibility relation - for it would allow a circumstance in which a stick slightly shorter than $S$ was used as a standard of a meter to be accessible from the one where $S$ has been used as a standard of meter.
} 
Then Kripke's claim would that, given that the length of stick $S$ (at $t_{0}$ ) is one meter, it may still be something other than a meter - say, $90 \mathrm{~cm}$ - which is absurd. (What is not absurd is that even if the length of stick $S$ is actually one meter, it might have happened to be something other than a meter.) On the other hand, the term ra priori< appears to be implicitly relativized to those circumstances in which stick $S$ was used as a standard of a meter.

When Kripke says that "in this sense, there are contingent a priori truths, « the sense in which we may accept his claim is the one according to which the predicates scontingent< and sa priori< are relative to distinct circumstances. Contingency is relative to circumstances in which it is not settled what was used as a standard of a meter (while it is settled that the term >meter p picks up the length it actually picks up, viz. the equivalent of 39.37 inches). Apriority, on the other hand, is relative to circumstances in which it is settled that specifically the length of stick $S$ is used as a standard of a meter.

I shall now argue that if there is such a mismatch of relativization, then the idea of a priori contingent truths does not give us anything to be excited about.

Here is, again, the statement under consideration:

(A) Stick $S$ is one meter long (at $t_{0}$ ).

When we are asked about the epistemological or the metaphysical status of the truth expressed by $(\mathrm{A})$, there are several ways to answer the question, depending on what the epistemic and the modal predicate are relative to. Here are the main options:

1. With respect to any circumstance in which the agent has used the length of stick $S$ as a standard of a meter, the truth expressed by (A) is a priori. (TRUE)

2. The truth expressed by (A) is a priori tout court, that is to say, for any agent in any circumstance. (FALSE)

3. The truth expressed by $(\mathrm{A})$ is contingent with respect to any circumstance in which the agent has used stick $S$ as a standard of a meter. That is to say, from any such circumstance, there is an accessible circumstance in which stick $S$ isn't one meter long. (FALSE)

4. The truth expressed by (A) is contingent tout court, that is to say, there are circumstances in which stick $S$ isn't one meter long. (TRUE)

As indicated, I take claims 1 and 4 to be correct, and 2 and 3 to be incorrect. On the other hand, the following strike me as correct:

$2^{\prime}$. With respect to any circumstance in which the agent has not used stick $S$ as a standard of a meter, and in which the length used as a standard of a meter cannot be a priori identified with the length of stick $S$, the truth expressed by (A) is a posteriori. (TRUE) 
$3^{\prime}$. With respect to any circumstance in which it is taken for granted that the the length of the stick $S$ is used as a standard of a meter, the truth expressed by (A) is necessary. (TRUE)

Given the various ways in which the expressions under consideration may be disambiguated, we seem to be entitled to any of the following claims:

i. The truth expressed by (A) is a priori and contingent in one sense; namely, in the sense of 1 and 4.

ii. The truth expressed by (A) is a priori and necessary in another sense; namely, in the sense of 1 and $3^{\prime}$.

iii. The truth expressed by $(\mathrm{A})$ is a posteriori and contingent in yet a third sense; namely, that of $2^{\prime}$ and 4 .

iv. The truth expressed by $(\mathrm{A})$ is a posteriori and necessary in yet a fourth sense; namely, that of $2^{\prime}$ and $3^{\prime}$.

To be sure, it is difficult to devise a situation in which one would simply say that the truth of $(\mathrm{A})$ is a posteriori and necessary, as in iv. The difficulty lies in the fact that sa posteriori< and snecessary< would have to be implicitly relativized to distinct and, moreover, incompatible circumstances. By parity of reasoning, $\mathrm{i}$ should not be much better, given that the epistemic and the modal predicate are again relativized to distinct circumstances. The most appropriate thing to say is that the truth expressed by (A) is neither a priori tout court nor necessary tout court, and that it is a priori to the same extent to which it is necessary.

\section{One More Attempt (on Kripke’s Behalf)}

At this point, one might object that I have simply missed Kripke's point. For, consider a circumstance, call it Circ, in which the agent has used the length of stick $S$ as a standard of a meter; that is to say, a circumstance in which the expression "one meter " picks out as its reference the actual length of stick $S$ in that circumstance. Suppose that in Circ, stick $S$ is a bit longer than a meter, say, 40 inches (recall that $1 \mathrm{~m}$ is 39.37 in). What is, then, the epistemic status of the truth expressed by (A) with respect to Circ? One might want to say that it is an a priori truth, since in Circ, the meter has been defined as being the length of stick $S$ (hence smeter there stands for 40in, rather than 39.37) But one might also want to say that (A) expresses something that is false with respect to Circ, since, after all, stick $S$ in Circ is 40 inches long, which is a bit more than a meter. But then, one might continue, this must mean that the truth expressed by (A) (in the original setting) is only contingent, given that there are circumstances, such as Circ, in which it does not hold (even though stick $S$ has been used there, too, as a standard of a meter). 
And from this it would follow that, contrary to what I have suggested, that claim 3 is true:

3. The truth expressed by (A) is contingent with respect to any circum-stance in which the agent has used stick $S$ as a standard of a meter.

The reasoning that I have sketched is problematic. To see why, let me first articulate two assumptions on which it relies:

a1. The truth expressed by (A) is a priori with respect to circumstance $C$ iff $f_{\text {def }}$ : if sentence (A) were uttered in $C$, then any agent in $C$ would know a priori that that utterance of $(\mathrm{A})$ expresses a truth.

a2. The truth expressed by $(A)$ is contingent with respect to circumstance $C$ iff $_{\text {def }}$ : sentence (A), as uttered in the actual circumstances, expresses something that correctly characterizes the actual circumstances, while incorrectly characterizing some circumstance accessible from $C$.

In other words, according to this view, when we ask for the epistemic status of a truth expressed by a sentence, with respect to a circumstance, we consider the sentence as if it had been uttered in that circumstance. But when we ask for the metaphysical status of a truth expressed by a sentence, with respect to some circumstance, we consider the sentence as actually uttered, and we ask whether the other circumstance is correctly characterized by this utterance here and now. So again, there is a mismatch between what one is talking about when inquiring about the epistemic vs. the meta-physical status of »the truth expressed by (A). «To repair the mismatch, one might want to replace assumption a 2 with the following one:

a3. The truth expressed by (A) is contingent with respect to circumstance $C$ iff $f_{\text {def }}$ : sentence (A), as uttered in $C$, characterizes $C$ correctly, while incorrectly characterizing some circumstance accessible from $C$.

Given a3, Circ is not a circumstance with respect to which the truth expressed by (A) is at the same time a priori and contingent, and, furthermore, it is unclear how there could be such a circumstance, if we assume that once it is settled that the length of stick $S$ (at time $t_{0}$ ) was used as a standard of a meter, then it remains true, in all the accessible circumstances, that is was used as a standard of a meter.

The idea that one can have an a priori contingent truth relative to some particular circumstance may thus be interpreted in two ways. On the more straightforward interpretation, provided by a1 and a3, we get the startling, if not outright contradictory claim that one and the same truth is known, independently of empirical input, to be the case, and may still fail to be the case in that same circumstance in which it is known a priori. On the other interpretation, provided by 
a1 and a2, the idea seems to be that there is a single truth that is a priori and contingent. But as it turns out, $\mathrm{a} 2$ is about the truth expressed by a sentence uttered in the actual circumstances, while a1 is about what is expressed by a sentence hypothetically uttered in a different circumstance. Since those utterances express different truths, there is no single truth that may be said to be both a priori and contingent. ${ }^{3}$

\section{Kaplan on the Contingent A Priori}

David Kaplan has carried Kripke's idea of the contingent a priori into the realm of logic. Kaplan's suggestion is that there are logical truths that are contingent:

I wish to parallel [Kripke's] remarks on disconnecting the a priori and the necessary. The form of a prioricity that I will discuss is that of logical truth (in the logic of demonstratives) ... A truth of the logic of demonstratives, like »I am here now « need not be necessary. There are many such cases of logical truths which are not necessary. (1989: 538)

Kaplan focuses on allegedly logical yet contingent truths expressed by utterances of the sentence »I am here now. « And if, as seems plausible, logical truths are knowable a priori, then this would give us another instance of the contingent a priori.

Kaplan's example raises interesting issues of its own, some of which would take us astray in our discussion. Let me therefore begin by applying Kaplan's proposal to the issues discussed so far. (In section 6, I will turn to cases that directly involve indexicals, and to the issue of their logical, and not only epistemic, status.)

There appear to be two ways of »disconnecting the a priori and the necessary." One is to say that the same kind of entity is a priori or a posteriori and necessary or contingent, and that among those entities, some are at the same time a priori and contingent. This is the suggestion that we have been examining previously. We have assumed that what is or is not the case, what could or could not have failed to be the case, and what is known, a priori or a posteriori, to be or not to be the case, are always the same sort of entities (viz. »truths «). I hope to have shown that if it makes sense to say of something that it is a priori and contingent, it makes sense only provided that the predicates sa priori< and scontingent< are implicitly relativized to distinct circumstances.

\footnotetext{
${ }^{3}$ Insightful arguments against Kripke's proposal that there are contingent a priori truths have been previously given by Donnellan (1977), Dummett (1981), Evans (1979), et al., but any discussion of those falls beyond the scope of this paper.
} 
The other way of disconnecting the a priori and the necessary is to say that the entities that a priori or a posteriori are not the same as those that are necessary or contingent. That is, epistemic and metaphysical predicates would apply to different sorts of things. This is what Kaplan seems to be suggesting when he writes:

The bearers of logical truth and of contingency are different entities. It is the character that is logically true, producing a true content in every context. But it is the content that is contingent or necessary (1989: 530).

Let us apply Kaplan's idea to our working example. Reconsider:

(A) Stick $S$ is one meter long (at to).

Furthermore, let us assume that the following is a faithful paraphrase of A:

$\left(\mathrm{A}_{1}\right)$ The length (at $\left.t_{0}\right)$ of stick $S=$ one meter.

Kaplan would say that $\left(\mathrm{A}_{1}\right)$ expresses a certain content. Call this content $p$. Now, $p$ does not say that a meter is identical to itself. Rather, $p$ says that the relation of being the same length obtains between a meter and stick $S$ at time to. So, consider someone who has used the length of stick $S$ at time to as a standard of a meter. For that person, »a meter « will roughly mean the same as »the actual length of stick $S$ (at $t_{0}$..« We may use Kaplan's special device, dthat, to indicate that the embedded condition merely serves to single out the thing that actually satisfies that condition uniquely. Statement $\left(A_{1}\right)$ may be paraphrased, then, as follows:

$\left(\mathrm{A}_{2}\right)$ The length at to of stick $S=\operatorname{dthat}($ the length at to of stick $S$ ).

Here is the gist of Kaplan's proposal. The content expressed by $\left(\mathrm{A}_{2}\right)$ is that the relation of being the same length obtains between the meter itself (which is what the dthat-expression picks out as its reference) and stick $S$. This content is contingent, since there are possible circumstances in which stick $S$ is longer or shorter than a meter. However, the character of $\left(\mathrm{A}_{2}\right)$, by means of which the content comes to be expressed, can only express something that is true in the circumstances in which $\left(\mathrm{A}_{2}\right)$ is uttered, and, in this respect, the sentence in $\left(\mathrm{A}_{2}\right)$ is logically true, and its character is "a priori«. One might thus want to say that the truth expressed by $\left(\mathrm{A}_{2}\right)$ is contingent (because the content is) and a priori (because the character is).

My concern is that it is not clear how the notion of an a priori truth, in the sense of a truth known independently of any empirical input, is supposed to apply to characters. For, characters are merely routes from a sentence in a context to its content, while contents are supposed to be things that are believed or known. Indeed, Kaplan himself introduced an »Epistemic Principle« that says: »Object of thoughts = Contents $«($ Kaplan 1989: 530).

One might find the following definition promising: 


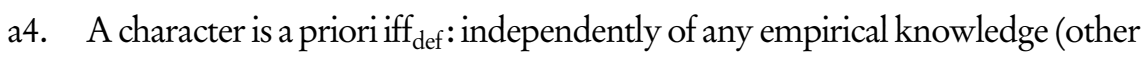
than the required knowledge of language) any agent knows that if sentence $A$ has that character, then the content expressed by any utterance of $A$ obtains in the circumstances in which the utterance is made.

On this interpretation, to say that a character is a priori amounts, in fact, to saying that a certain content that is about this character is known to be the case independently of any empirical knowledge (other than the required knowledge of language). The content that is a priori is the content that says that any utterance of a sentence with the character at stake expresses a content that obtains in the circumstances of the utterance. But what follows from this is that the predicates sa priori< and ^necessary < are no longer disconnected in virtue of holding of different sorts of entities. For, characters are a priori only in a derivative sense, while what is in fact a priori are contents about characters. What is more, such "a priori« contents are not a priori in any fruitful sense, because they depend on the knowledge of what the given expressions mean. More importantly, there is no single content that can be known independently of experience and yet fail to be the case, hence there is nothing at the same time a priori and contingent.

\section{One more Attempt (on Kaplan's Behalf)}

Adherents to Kaplan's proposal might acknowledge that there is nothing contingent and a priori, in the sense that there are no contents at the same time contingent and a priori. But they might persist on the idea that there are "a priori characters, " i. e. characters that generate contingent contents, but with which we may associate a priori knowable contents, such as the content that says that any utterance of a sentence with that character expresses a content that obtains in the circumstances of utterance. This very idea, they might continue, is a startling result per se, since it suggests that contingent truths can be known under a priori characters. ${ }^{4}$

I want to show that this idea is pointless. I will argue that in Kaplan's framework, any contingent content that can be known at all can be known under an a priori character. And if every contingent truth is an instance of the contingent a priori, in the sense that the contingent content is knowable under an a priori character, the idea of the contingent a priori becomes trivial. So here comes the argument.

Consider some contingent content that says that object b has property $\mathrm{P}$, noted $\mathrm{P}(\mathrm{b})$. Suppose that in circumstance $c$ at time $t$, agent $a$ comes to know that $\mathrm{P}(\mathrm{b})$ is

\footnotetext{
${ }^{4}$ Characters are closely related to modes of presentation. The idea of knowing something "under " a character comes from the idea that knowledge, and cognitive processes in general, are mediated by modes of presentation.
} 
the case, and that he comes to know it under the straightforward character of $\gg b$ has $\mathrm{P}$.« The same content, $\mathrm{P}(\mathrm{b})$, will be expressed by the following sentence:

(1) Dthat(the only object such that in $c$ at $t, a$ comes to know that it has $\mathrm{P}$ ) has $\mathrm{P}$.

The content expressed by (1) is, to be sure, contingent. On the other hand, it takes little to realize that the character of (1) is "a priori, « since it always yields a content that obtains in the circumstances in which the sentences is uttered. ${ }^{5}$

The lesson to be drawn is that there is nothing illuminating about contingent contents that can be known »under a priori characters." The reason is that the features of the a priori associated with such characters are, in fact, dissociated from their contingent contents. For, if I know that $\mathrm{P}(\mathrm{b})$, then I can also know it under an a priori character, because I know, independently of any empirical knowledge (other than the required knowledge of language) that if the sentence in (1) is uttered, its content (whenever it expresses one) will obtain in that circumstance. This »meta-content, " admittedly known a priori, is about the character of (1), while the contingent content that this character expresses is about object $b$ and property $\mathrm{P}$.

I have just shown how any content that ascribes a property to an object and that can come to be known, can subsequently be known under an a priori character. It is easy to generalize this strategy to show that any content that can come to be known, can subsequently be known under an a priori character. There is another way of getting at the same conclusion, perhaps more direct. Consider some clearly a posteriori and clearly contingent content, such as:

(2) On November 11, 2007, it was sunny in Paris.

As it turns out, (2) is actually true, hence (2) expresses a contingent and, presumably, a posteriori truth. But now, consider:

(3) On November 11, 2007, it was sunny in Paris if, and only if, on November 11, 2007, it was actually sunny in Paris.

It takes little to realize that the »truth-conditional profile« of (2) is the same as that of (3). That is to say, given that the right hand side of the bi-conditional in (3) is true (since it was actually sunny in Paris on that day), (3) is true with respect to the same circumstances (or possible worlds) with respect to which (2) is true, namely, those in which it was sunny in Paris on 11/11/2007.

The upshot of this example is to demonstrate that any contingent content $p$ that is known to be actually true, can be known under the a priori character of $» p$

\footnotetext{
${ }^{5}$ Note that if the sentence in (1) is used in a context in which a does not come to know that $\mathrm{P}(\mathrm{b})$, no content will be expressed. But my claim is that any content that can come to be known can subsequently be known under an a priori character.
} 
iff actually $p . \ll^{6}$ In turn, this strongly suggests that the idea of contingent contents known under a priori character is of little interest.

\section{Are there Contingent Logical Truths?}

I have argued, against Kripke and Kaplan, that there are no a priori contingent truths, and that the notion of contingent truths known »under a priori characters « is of no interest. But it may be objected, rightly, that what Kaplan is really concerned with are contingent logical, rather than a priori, truths. So what I want to do in this last section is briefly address the issue of contingent logical truths.

It will be helpful to start with considerations to which Kaplan appeals to support the idea that there are contingent logical truths. He writes:

[ $\mathrm{I}$ am here now $]$ is deeply and in some sense universally true. One need only understand the meaning of [it] to know that it cannot be uttered falsely. (1989: 509)

As noted earlier, according to Kaplan, the truth expressed by an utterance of the sentence $>\mathrm{I}$ am here now $<$ is a truth of logic, yet it is not a necessary truth. But what are the reasons to take it to be a truth of logic, to begin with? Kaplan thinks that it is because the meaning itself of the words > $\mathrm{K}$, >am<, >here $<$ and now $<$, warrants that any utterance of that sentence will express a truth.

The conception of logical truth as »truth in virtue of meaning « is familiar, and applies to the usual, uncontroversial cases of logical truth. Thus »If every student owns a book, and if John is a student, then John owns a book «, is warranted to expresses truth merely in virtue of the meaning of the words if $<$, sthen<, >and<, and severy ${ }^{7}$ ?

However, what appears to have gone unnoticed in Kaplan's remarks is that in the case of $>\mathrm{I}$ am here now $<$, knowing the meaning is, in fact, not enough in order to know that an utterance of that sentence will express a truth. For, the meaning only tells you that the speaker, whoever he or she may be, is at the place of utterance at the time of utterance. But the meaning itself does not warrant that the speaker actually is at the place of utterance at the time of utterance. The latter, while required in order to determine that $\mathrm{I}$ am here now< expresses a

\footnotetext{
${ }^{6}$ I am grateful to Mark Crimmins (p.c.) for drawing my attention to this case.

${ }^{7}$ As Nikola Kompa has pointed out to me, it is often thought that the idea of "truth in virtue of meaning « captures the notion of analytic, rather than logical, truth. So for example, one might want to say that »All bachelors are unmarried « is an analytic truth, but not a truth of logic. I should say, however, that for the purposes of my discussion, the distinction (if there is one) between logical and analytic truth may be safely set aside, because, as we could see from the quoted passage, Kaplan himself appears to assume that being true in virtue of meaning is sufficient for being logically true, and what I will show is that the sentences that he is considering (viz. »I am here now « and $» F$ iff actually $\mathrm{F} \ll)$ are, in fact, not true merely in virtue of their meaning.
} 
truth, is an additional premise, the knowledge of which is derived from empirical generalization over facts about utterances made in ordinary circumstances, whose speakers typically are at the place of utterance at the time of utterance. However, the mere possibility of utterances that violate this generalization is enough to undermine the logical status of $>\mathrm{I}$ am here now $<{ }^{8}$

Leaving aside the controversial $>I$ am here now $<$, let me turn to sentences of the form »P if and only if actually $\mathrm{P}$ «, such as (3) above, which can be used to make the same point that Kaplan tried to make with »I am here now «. As Kaplan might say, one only need understand the meaning of if and only if $<$ and of sactually< in order to know that an utterance of, say, (3), cannot be uttered falsely. Yet, the truth expressed by (3) is arguably not necessary. For, if it were, then the following would be true:

(4) Necessarily, it was sunny in Paris on Nov 11, 2007, if, and only if, it was actually sunny in Paris on Nov 11, 2007.

But (4) is false, given that it need not have happened that it would be sunny in Paris on Nov 11, 2007. ${ }^{9}$

If there are indeed logical truths that fail the necessitation rule, hence logical truths that are not necessary, then $» \mathrm{P}$ iff actually $\mathrm{P}$ « is the clearest and the least controversial example of such a truth. But even here, how strong are the motivations for taking it to be a truth of logic? One motivation was the idea that the meaning of sif and only if $<$ and of ractually< warrants any utterance of this sentence to express a truth. But even this idea may be questioned. For, it relies on the assumption that the world that is relevant to determining the truth value of an utterance must be the actual world, i.e. the world in which the utterance is made and to which the indexical sactually< refers. But there is nothing inconsistent in the idea that some world other than the one in which the utterance is made (and with respect to which indexicals are interpreted) should determine the truth value of the utterance at stake. Consider this sentence:

(5) There is much less poverty and disease than there actually is.

As it stands on its own, (5) has something of a paradoxical feel to it. But suppose that (5) is asserted by a speaker who is talking about the world of her dreams, the world as she would like it to be. Then (5) will be true iff in that possible world

\footnotetext{
${ }^{8}$ Note that we only need to assume that it is logically possible that a speaker is not at the place of utterance at the time of utterance in order to show that $\mathrm{I}$ am here now $<$ does not deserve the status of logical truth. But it may be argued, and has been argued, that there are such utterances. Broad-casted speech is the case at point: e.g. »I am not here now « recorded on an answering machine, and the like. For discussion, see e.g. Predelli (1998).

${ }^{9}$ Recall that $>$ Necessarily $\mathrm{F}<$ is true in a given world iff $>\mathrm{F}<$ is true in every possible world. Hence, given that in our world it was sunny in Paris on Nov 11, 2007, (4) is true in our world iff in every possible world it was sunny in Paris on 11-11-2007.
} 
there is much less poverty and disease than there is in our world. In other words, (5) may be seen as an example in which the world responsible for determining truth value and the world responsible for interpreting the indexical sactually< come apart.

Once again, the mere possibility of there being utterances for which the worlds playing those two roles diverge is enough to cast doubt on the idea that the truth expressed by a sentence of the form $>\mathrm{P}$ iff actually $\mathrm{P}<$, as in (3), is a truth of logic. And while it remains true that in general, sentences such as (3) express truth, the truth that they express is not truth merely in virtue of meaning, but depends on an empirical generalization, namely, the world that the utterance is about, and with respect to which it is evaluated for truth, should be the world in which the utterance is actually made, and in which the indexicals receive their interpretation. ${ }^{10}$

Are there, then, compelling examples of contingent logical truth? The answer will largely depend on one's criteria for deciding what should count as a truth of logic in the first place. The criterion of its being "truth in virtue of meaning " was arguably Kaplan's preferred criterion. But the cases that seemed to fall under this criterion, such as »I am here now « and " $p$ iff actually $p$ «, are less compelling than might have seemed at first. For, the systematicity with which they express truth appears to be due to contingent facts about utterances (e.g. that the speaker should be at the place of utterance at the time of utterance, or that the world talked about is the same as the world in which the utterance is made).

In deciding what to count as a truth of logic, another criterion that comes to mind is that truths of logic should obey the rule of necessitation. But if we endorse this criterion, then contingent logical truths get abolished by definition. So what other compelling criteria are there? Well, one might think that a necessary (albeit not sufficient) criterion is that logical truths be knowable a priori. And again, at a first glance, one might think that »I am here now « and »p iff actually $p$ « fall under this criterion. However, the arguments against the contingent a priori provided in the previous sections are applicable to these cases as well, and will show that neither of these expresses a priori truths. (In particular, the conditions under which the truth of " $p$ iff actually $p$ « may come to be known are the very same conditions as those under which the truth expressed by 'p< itself may come to be known; cf. section 5.)

The view that there are contingent logical truths does not seem, then, to be much better off than the view that there are contingent a priori truths. We saw, in section 2, that one can say that some truth is both contingent and a priori, but that this will only make sense if the predicates >contingent $<$ and $>$ a priori are implicitly relativized to distinct circumstances. Perhaps one can also say that some truth is

${ }^{10}$ For further discussion, see Predelli and Stojanovic (2008). 
both contingent and a truth of logic, but what sense this will make will depend on one's criteria for deciding what to count as a truth of logic. The most obvious and plausible criteria (namely, that it should be truth in virtue of meaning, that it should obey the rule of necessitation, and that it is in principle knowable a priori) all predict that truths expressed by »I am here now « and by sentences of the form " $p$ if and only if actually p « are not logical truths. This does not show yet that there cannot be contingent logical truths, but it sheds doubt on the viability of the idea. Just as the contingent a priori appears to be more of an illusion than of an interesting philosophical discovery, a logic that allows for valid sentences that fail the necessitation rule looks more like an ingenious toy-logic than a valuable advance in philosophy of logic. ${ }^{11}$

\section{REFERENCES}

Donnellan, Keith (1997). »The Contingent A Priori and Rigid Designators«,Midwest Studies in Philosophy 2.

Dummett, Michael. (1981), Frege: Philosophy of Language, London Duckworth.

Evans, Gareth. (1979), "Reference and Contingency «, The Monist 62 (1979); reprinted in Evans, G. Collected Papers, Oxford UP (1985): 178-213.

Kaplan, David. (1989), »Demonstratives«, in Almog, J., Perry, J., Wettstein, H. (eds.), Themes from Kaplan, Oxford UP.

KRIPKE, Saul. (1980), Naming and Necessity, Oxford UP.

Predelli, Stefano. (1998), »I Am Not Here Now «, Analysis 58: 107-115.

- and Stojanovic, Isidora. (2008), "Semantic Relativism and the Logic of Indexicals." in Garcia-Carpintero, M. and Kolbel, M. (eds.), Relative Truth, Oxford UP: 63-80.

\footnotetext{
${ }^{11}$ I would like to thank Nikola Kompa, Christian Nimtz and Christian Suhm for the invitation to contribute to the present volume, and in particular Nikola, for also providing helpful comments on an earlier draft of the paper.
} 